\title{
The experience of canakinumab in renal amyloidosis secondary to Familial Mediterranean fever
}

\author{
Betul Sozeri ${ }^{1 *}$, Nesrin Gulez ${ }^{2}$, Malik Ergin ${ }^{3}$ and Erkin Serdaroglu ${ }^{4}$
}

\begin{abstract}
Introduction: Familial Mediterranean fever (FMF) is an autosomal recessive disease characterized by self-limited recurrent attacks of fever and serositis. Patients may develop renal amyloidosis. Colchicine prevents attacks and renal amyloidosis. Five to $10 \%$ of the patients with FMF are resistant or intolerant to colchicine.
\end{abstract}

Case description: Herein, we reported our experience with clinical-laboratory features and treatment responses of a pediatric FMF patient with amyloidosis treated with canakinumab. We observed a significant decrease in proteinuria and increase growth in the patient.

Discussion and evaluation: The most serious complication of FMF is the development of AA type amyloidosis which is characterized by proteinuria. Colchicine is the prototype drug that decreases production of amyloidogenic precursor protein. Occasionally, colchicine inadequate patient is observed, as in our case. Canakinumab is a human anti-IL-1 $\beta$ monoclonal antibody. Previously, canakinumab efficacy were shown in a limited number of studies.

Conclusions: Our data, though limited to only one patient, emphasize that therapeutic intervention with canakinumab seems to be improve kidney function in colchicine-resistant FMF with renal amyloidosis.

Keywords: Familial Mediterranean fever, Amyloidosis, Child, Canakinumab

\section{Background}

Familial Mediterranean fever (FMF) is a genetic, autoinflammatory disease, characterized by acute episodes of serosal and cutaneous inflammation, expressed with pain, fever, neutrophilia, and intense acute-phase response, caused by activation of the innate immune system [1]. The FMF gene, named MEFV, is located on the short arm of chromosome $16[2,3]$. It encodes a 781-amino acid protein called pyrin or marenostrin which is expressed mostly in neutrophils and acts in controlling inflammation by deactivating inflammatory peptides [4,5]. Mutated forms of it may be involved in a series of reactions that ultimately enhance the overexpression of IL-1b and consequent inflammation [1].

FMF has been associated with an increased risk for secondary amyloidosis, mainly affecting the renal and

\footnotetext{
* Correspondence: betulsozeri@yahoo.com

'Department of Pediatric Rheumatology, Ege University Faculty of Medicine, Izmir, Turkey

Full list of author information is available at the end of the article
}

vascular function in untreated or insufficiently treated patients with FMF. Amyloidosis is a progressive destructive disorder that results in organ dysfunction due to extracellular deposition of $N$ terminal fragments of serum amyloid A protein (SAA) in the form of insoluble amyloid fibrils [6]. Proteinuria is usually the earliest and most common clinical manifestation of AA amyloidosis in patients with inflammatory diseases [6].

The goal of therapy for FMF is the prevention of acute attacks, development, and progression of amyloidosis. Colchicine is the mainstay of therapy which decreases attack frequency and increases the quality of life in more than $60 \%$ of patients [7]. It also prevents SAA secretion and slows the progression of amyloidosis in patients with FMF [7]. Approximately $40 \%$ of FMF patients treated with colchicine have a partial remission showed in the Eurofever study [8]. Also, 5-10 \% of the patients were reported to be resistant; suffering from either more than six typical FMF attacks per year or more than three typical FMF attacks within 
4-6 months [9]. Several studies showed that the patients with FMF were successfully treated with agents blocking interleukin (IL)-1 activity due to the critical role of IL-1 in the pathogenesis FMF [10-14].

Canakinumab is a high-affinity human anti-IL1 $\beta$ monoclonal antibody of the IgG1/k isotype developed for the treatment of immune disorders, and it is highly specific for IL- $1 \beta$ and does not interfere with other IL-1-activated pathways.

We would like to share our experience of a patient with colchicine-resistant FMF and renal amyloidosis, whose treatment with canakinumab substantially improved renal functions and reduced proteinuria over a period of 26 months.

\section{Case presentation}

A 14-year-old male with colchicine-resistant FMF and amyloidosis was admitted for the first time in May 2013. He was born to parents of second-degree consanguineous marriage. He had taken regular colchicine therapy (2 g/ day) and ramipril ( $5 \mathrm{mg} /$ day) for proteinuria for a year.

From his history, he had recurrent FMF attacks associated with severe abdominal pain, joint pain, and fever, which had begun at the age of four. However, he was hospitalized for the first time at the age of 7 years because of intermittent febrile episodes with chills, abdominal pain, and arthritis involving ankle joints. Splenomegaly was found a year later. His attacks continued once a month until he was diagnosed with FMF at 13 years old. At that time, he had proteinuria, splenomegaly, and growth retardation. He was homozygous for the M694V mutation in MEFV gene. Also, microhematuria and proteinuria $(38 \mathrm{mg} / \mathrm{m} 2 / \mathrm{h}$ ) was found at his urinalysis. Serum creatinine level was $1.1 \mathrm{mg} / \mathrm{dl}$, and creatinine clearance was $89 \mathrm{~mL} /$ min. Diagnosis of chronic kidney disease (CKD) with AA amyloidosis was established via renal biopsy (Fig. 1). Severe glomerular amyloidosis plus mild vascular and mild interstitial amyloidosis was found in his kidney biopsy. Colchicine therapy was started with a dose of $1 \mathrm{mg} /$ day. In the first month of treatment, he was clinically normal and his C-reactive protein (CRP) level was within normal limits. At his 6-month follow up, the dose of colchicine had to be increased ( $2 \mathrm{~g} /$ day) due to an increased attack rate (5 attacks per 6 months) despite the regular use of drugs.

The laboratory findings on admission revealed an elevated CRP $(184 \mathrm{mg} / \mathrm{dL})$ and SAA $(645 \mathrm{mg} / \mathrm{dL})$ levels. Nephrotic range proteinuria was found in urine analysis (43 mg/m2/h). Because of his poor response to colchicine, severe growth retardation, and severe proteinuria due to amyloidosis, we decided to start canakinumab treatment (150 mg/month/sc) in June 2013. Informed consent about the potential side effects and the empirical aspects of the therapy was obtained. One month later, the patient was symptom-free and the inflammatory parameters almost normalized. After 26 months of follow-up, with canakinumab treatment, his complaints, inflammatory parameters (CRP; $0.03 \mathrm{mg} / \mathrm{dl}$ and SAA; $3.81 \mathrm{mg} / \mathrm{dl}$ ) and proteinuria were decreased. Splenomegaly was decreased and also his growth rate returned to normal (Fig. 2), after canakinumab therapy. The mean height SDS before therapy was significantly lower than after canakinumab $(-2.12 \pm 0,11$ vs $-1.71 \pm 0,14, P=0,009$ ) (Fig. 3 ). He was kept on $2 \mathrm{mg}$ of colchicine daily. No side effects were noted.

\section{Discussion and evaluation}

The most serious complication of FMF is the development of AA type amyloidosis which is characterized by proteinuria and is typically progressive and leads to end-
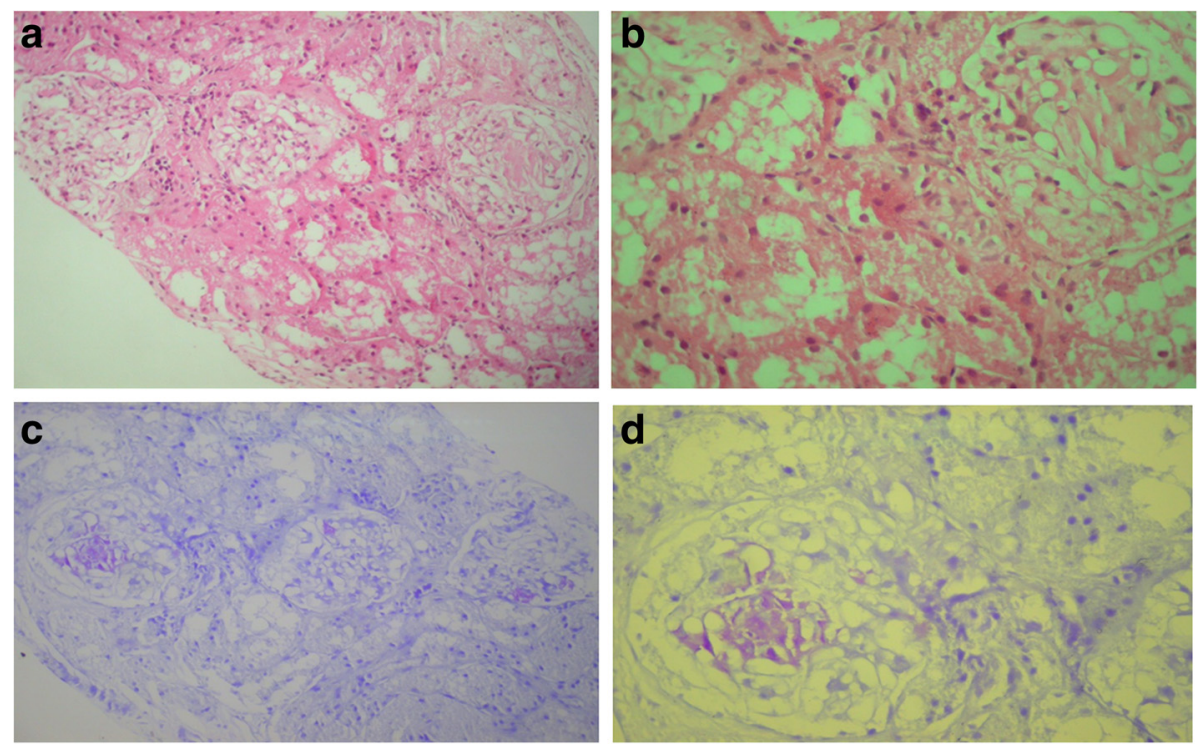

Fig. 1 Renal amyloid deposition was diagnosed in glomerulus by two different staining 


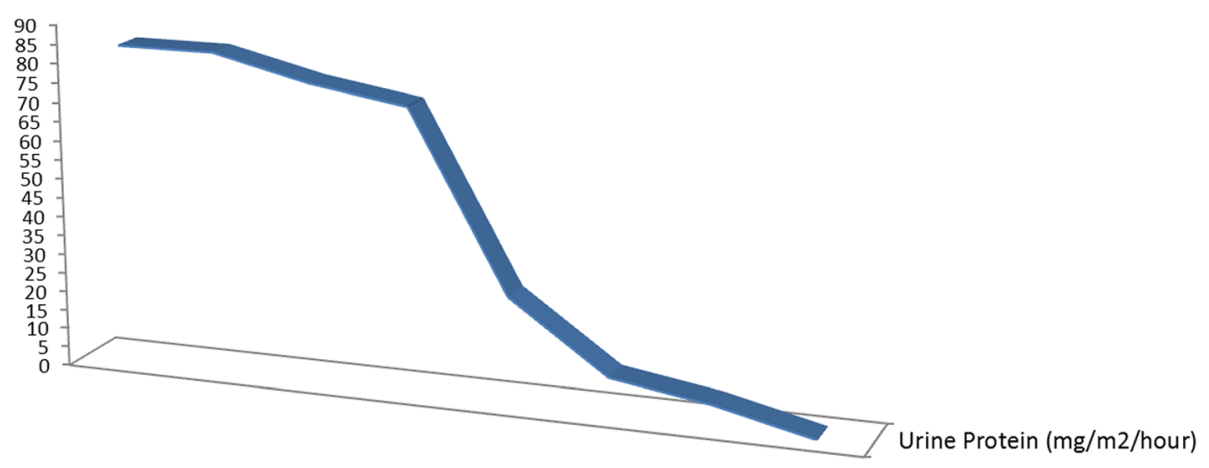

Fig. 2 Effect of canakinumab on proteinuria (miligrams/m2(per hour)

stage vital organ involvement, first diagnosed by Mamou and Cattan in 1952 [15]. Renal amyloidosis has been shown to cause mortality in FMF patients [16]. In the series reported by the Turkish FMF study group, the presenting clinical features of the patients with amyloidosis secondary to FMF were as follows: 32 \% proteinuria, $40 \%$ nephrotic syndrome, and $28 \%$ chronic renal failure [17]. The M694V mutation has been shown to be a strong risk factor of developing amyloidosis in different ethnic groups [17]. The production of the precursor to SAA is the main step in the pathogenesis of amyloidosis, which is produced by inflammatory signals, IL-1 $\beta$, tumor necrosis factor (TNF)- $\alpha$, and IL-6 [18]. The "gold standard" for the diagnosis of amyloidosis remains a tissue biopsy demonstrating characteristic hematoxylin and eosin changes and Congo red birefringence or metachromatic pink-violet staining with methyl violet or crystal violet [19]. The patient's renal biopsy was evaluated with the scoring system defined for renal amyloidosis and was found as severe glomerular amyloidosis plus mild vascular and mild interstitial amyloidosis. The scoring system proposed by Sen $\mathrm{S}$ et al. [20] in 2010 and compared to clinical parameters by Castano et al. [21]. They have demonstrated that the severity of glomerular amyloid deposition was correlated the risk of developing end-stage renal disease and increase the risk for premature death [21]. Also they have reported proteinuria, and serum albumin

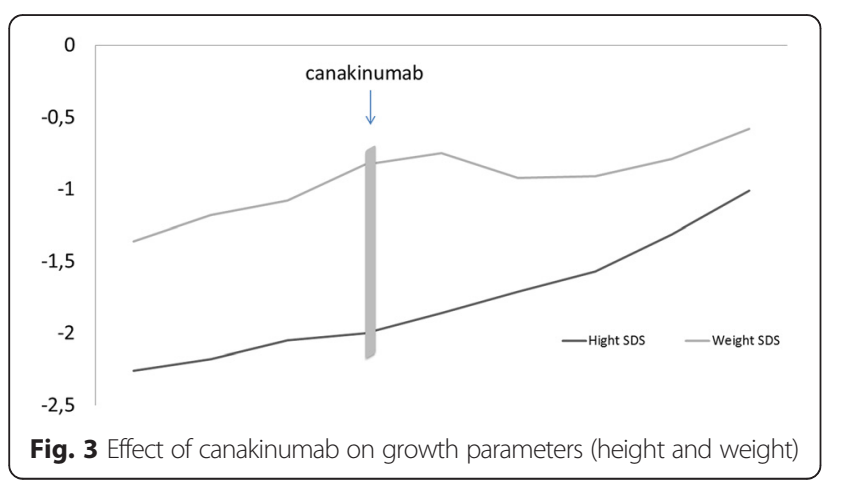

and serum creatinine levels were correlated with degree of amyloidosis [21]. Also, the degree of amyloidosis was measured through parameters such as SAA protein and serum amyloid P (SAP) scintigraphy [18, 22].

Herein, we reported a FMF patient with biopsy-proven renal amyloidosis and growth retardation. He had various risk factors for amyloidosis including carrying the M694V allele, family history, and late diagnosis.

Pro-inflammatory cytokines may modulate growth patterns in children with inflammatory diseases through both systemic and local effects of the GH/IGF-1 axes [23]. It has been shown that FMF patients catch up to their growth with an effective colchicine treatment [24-26].

The aim of treatment in AA amyloidosis is the suppression, as complete as possible, of the inflammatory process responsible for the overwhelming SAA production. Colchicine is the prototype drug that decreases production of amyloidogenic precursor protein. Occasionally, colchicine inadequate patient is observed, as in our case. In such circumstances, anti IL-1 treatment options come into play. Anti- IL-1 drugs impact on amyloidosis is still unknown. Previously, there were reports of some adult cases with successful use of anti IL-1 therapy (anakinra) in renal transplant recipients [11, 12]. There are few data from pediatric patients in literature. Bilginer Y et al. [27] reported a patient who was diagnosed with FMF and Behçet's disease and proteinuria, with normal kidney function after 18 months of anakinra treatment. Recently, Ozcakar et al. [28] showed one child patient with nephrotic syndrome in whom partial remission had been observed after 12 months of anakinra therapy.

Canakinumab is a human anti-IL-1 $\beta$ monoclonal antibody. Its mode of action is based on the neutralization of IL-1 $\beta$ signaling which may result in the suppression of the inflammation process. To the best of our knowledge, about de novo canakinumab treatment in FMF patients with AA amyloidosis is limited. Topaloglu R et al. [29] reported a patient diagnosed amyloidosis was successful treated with canakinumab. 
Cetin P et al. [12] reported experience in 20 cases of adult and pediatric FMF colchicine-resistant patients who were treated with anti-IL-1 agents. Twelve patients were receiving anakinra, and eight patients were treated with canakinumab. The number of monthly and yearly attacks after IL-1 treatment significantly decreased after the biologic agent $(p<0.05)$. Hashkes $\mathrm{P}$ et al. [13] conducted an open-label, single-arm study in seven children with colchicine-resistant FMF. Six participants met the primary outcome with $\geq 50 \%$ reduction (range 76-100 \%) in the FMF attack rate. The median 28-day time-adjusted attack rate decreased from 2.7 to 0.3 (89\%). Canakinumab was shown to be effective in treating pediatric patients with colchicine-resistant FMF in this study. Another study reported that in children with colchicine-resistant FMF, monthly canakinumab $150 \mathrm{mg}$ subcutaneous injections prevented FMF attacks in patients with frequent attacks, and only one of nine patients experienced an attack during the treatment period [14].

\section{Conclusions}

Canakinumab has demonstrated a sustained clinical response in the patient affected by colchicine-resistant FMF and biopsy-proven renal amyloid deposits, blocking and significantly reducing renal damage progression. Also, we observed the normalization of the markers of inflammation inc. SAA, and the reduction of proteinuria in an overall period. Moreover, his growth pattern was improved with therapy. No adverse events, namely infectious episodes, were reported in our patient during treatment with canakinumab. We did not consider making a repeat biopsy for proteinuria completely regressed.

Our report emphasizes that the therapeutic intervention with canakinumab can treat colchicine-resistant FMF by suppressing inflammation and to prevent its most life-threatening complication, amyloidosis-related proteinuria. Further evaluations are needed in order to confirm the positive effect of canakinumab.

\section{Abbreviations}

CKD, chronic kidney disease; CRP, C-reactive protein; FMF, Familial Mediterranean fever; IL, interleukin; SAA, serum amyloid A protein; TNF, tumor necrosis factor

\section{Authors' contributions}

BS and NG were in charge of the patient's treatment and care in hospital and drafted the manuscript. BS also supervised the management of patient and revised the final manuscript for submission. ME diagnosed the patient's kidney biopsy. SE was in charge of the diagnosis of renal biopsy and helped in drafting the manuscript. All authors read and approved the final manuscript.

\section{Competing interests}

The authors declare that they have no competing interests.

\section{Ethics approval and consent to participate}

Written informed consent was obtained from the patient for publication of this Case report and any accompanying images. A copy of the written consent is available for review by the Editor of this journal.

\section{Author details}

'Department of Pediatric Rheumatology, Ege University Faculty of Medicine, Izmir, Turkey. ${ }^{2}$ Dr. Behcet Uz Children Diseases Teaching and Research Hospital Pediatric Immunology and Rheumatology, Izmir, Turkey. ${ }^{3}$ Dr. Behcet Uz Children Diseases Teaching and Research Hospital Pathology, Izmir, Turkey. ${ }^{4}$ Dr. Behcet Uz Children Diseases Teaching and Research Hospital Pediatric Nephrology, Izmir, Turkey.

Received: 13 December 2015 Accepted: 19 July 2016

Published online: 15 August 2016

\section{References}

1. Ben-Zvi I, Livneh A (2011) Chronic inflammation in FMF: markers, risk factors, outcomes and therapy. Nat Rev Rheumatol 7:105-112

2. The International FMF Consortium (1997) Ancient missense mutations in a new member of the RoRet gene family are likely to cause familial Mediterranean fever. Cell 90:797

3. French FMF Consortium (1997) A candidate gene for familial Mediterranean fever. Nat Genet 17:25

4. Grattagliano I, Bonfrate L, Ruggiero V, Scaccianoce G, Palasciano G, Portincasa P (2014) Novel therapeutics for the treatment of familial Mediterranean fever: from colchicine to biologics. Clin Pharmacol Ther 95:89-97

5. Ozen S, Bilginer Y (2014) A clinical guide to autoinflammatory diseases: Familial Mediterranean fever and next-of-kin. Nat Rev Rheumatol 10:135-147

6. Merlini G, Bellotti V (2003) Molecular mechanisms of amyloidosis. N Engl J Med 349:583-596

7. Hentgen V, Grateau G, Kone-Paut I, Livneh A, Padeh S, Rozenbaum M, Amselem S, Gershoni-Baruch R, Touitou I, Ben-Chetrit E (2013) Evidencebased recommendations for the practical management of Familial Mediterranean fever. Semin Arthritis Rheum 43:387-391

8. Ter Haar N, Lachmann H, Ozen S, Woo P, Uziel Y, Modesto C, Koné-Paut I, Cantarini L, Insalaco A, Neven B, Hofer M, Rigante D, Al-Mayouf S, Touitou I, Gallizzi R, Papadopoulou-Alataki E, Martino S, Kuemmerle-Deschner J, Obici L, lagaru N, Simon A, Nielsen S, Martini A, Ruperto N, Gattorno M, Frenkel J, Paediatric Rheumatology International Trials Organisation (PRINTO) and the Eurofever/Eurotraps Projects (2013) Treatment of autoinflammatory diseases: results from the Eurofever Registry and a literature review. Ann Rheum Dis 72:678-685

9. Lidar M, Scherrmann JM, Shinar Y, Chetrit A, Niel E, Gershoni-Baruch R, Langevitz P, Livneh A (2004) Colchicine nonresponsiveness in familial Mediterranean fever: clinical, genetic, pharmacokinetic, and socioeconomic characterization. Semin Arthritis Rheum 33:273-282

10. Mitroulis I, Skendros P, Ritis K (2010) Targeting IL-1beta in disease; the expanding role of NLRP3 inflammasome. Eur J Intern Med 21:157-163

11. Moser C, Pohl G, Haslinger I, Knapp S, Rowczenio D, Russel T, Lachmann HJ, Lang U, Kovarik J (2009) Successful treatment of familial Mediterranean fever with Anakinra and outcome after renal transplantation. Nephrol Dial Transplant 24:676-678

12. Cetin P, Sari I, Sozeri B, Cam O, Birlik M, Akkoc N, Onen F, Akar S (2015) Efficacy of interleukin-1 targeting treatments in patients with familial Mediterranean fever. Inflammation 38:27-31

13. Hashkes P, Butbul Aviel Y, Lubin S, Ben-Dayan E, Tseng L, Brik R (2014) A76: long-term efficacy of canakinumab in childhood colchicine resistant familial mediterranean Fever. Arthritis Rheumatol 66:108

14. Gül A, Ozdogan H, Erer B, Ugurlu S, Kasapcopur O, Davis N, Sevgi S (2015) Efficacy and safety of canakinumab in adolescents and adults with colchicine-resistant familial Mediterranean fever. Arthritis Res Ther 17:243

15. Mamou H, Cattan R (1952) La maladie periodique sur 14 cas personnels dont 8 compliqués de nephropathies. Semaine hop Paris 28:1062

16. Twig G, Livneh A, Vivante A, Afek A, Shamiss A, Derazne E, Tzur D, Ben-Zvi I, Tirosh A, Barchana M, Shohat T, Golan E, Amital H (2014) Mortality risk factors associated with Familial Mediterranean fever among a cohort of 1.25 million adolescents. Ann Rheum Dis 73:704-709

17. Tunca M, Akar S, Onen F, Ozdogan H, Kasapcopur O, Yalcinkaya F, Tutar E, Ozen S, Topaloglu R, Yilmaz E, Arici M, Bakkaloglu A, Besbas N, Akpolat T, Dinc A, Erken E, Turkish FMF Study Group (2005) Familial Mediterranean fever (FMF) in Turkey: results of a nationwide multicenter study. Medicine (Baltimore) 84:1-11

18. Lachmann HJ, Goodman HJ, Gilbertson JA, Gallimore JR, Sabin CA, Gillmore JD, Hawkins PN (2007) Natural history and outcome in systemic AA amyloidosis. N Engl J Med 356:2361-237 
19. Bennhold H (1922) spezifische Amyloidfarbung mit Kongorot. Munch Med Wochenschr 69:1537-1538

20. Sen S, Sarsik B (2010) A proposed histopathologic classification, scoring, and grading system for renal amyloidosis: standardization of renal amyloid biopsy report. Arch Pathol Lab Med 134:532-544

21. Castano E, Palmer MB, Vigneault C, Luciano R, Wong S, Moeckel G (2015) Comparison of amyloid deposition in human kidney biopsies as predictor of poor patient outcome. BMC Nephrol 16:64

22. Oner A, Erdogan O, Demircin G, Bulbul M, Memis L (2003) Efficacy of colchicine therapy in amyloid nephropathy of familial Mediterranean fever. Pediatr Nephrol 18:521-526

23. MacRae VE, Wong SC, Farquharson C, Ahmed SF (2006) Cytokine actions in growth disorders associated with pediatric chronic inflammatory diseases (review). Int J Mol Med 18:1011-1018

24. Zung A, Barash G, Zadik Z, Barash J (2006) Familial Mediterranean fever and growth: effect of disease severity and colchicine treatment. J Pediatr Endocrinol 19:15

25. Türkmen M, Soylu OB, Kasap B, Güneş S, Tüfekçi O, Soylu A, Erçal D, Kavukçu $S$ (2008) Growth in Familial Mediterranean fever: effect of attack rate, genotype and colchicine treatment. J Pediatr Endocrinol Metab 21:789-792

26. Sozeri B, Yilmaz E, Mir S, Berdeli A (2011) Effect of colchicine-resistant Familial Mediterranean fever on growth parameters. Archives of Rheum 26:1-5

27. Bilginer $Y$, Ayaz NA, Ozen S (2010) Anti-IL-1 treatment for secondary amyloidosis in an adolescent with FMF and Behçet's disease. Clin Rheumatol 29:209-210

28. Ozçakar ZB, Ozdel S, Yılmaz S, Kurt-Sükür ED, Ekim M, Yalçınkaya F (2014) Anti-IL-1 treatment in Familial Mediterranean fever and related amyloidosis. Clin Rheumatol 35:441-446

29. Topaloglu R, Batu ED, Orhan D, Ozen S, Besbas N (2015) Anti-interleukin 1 treatment in secondary amyloidosis associated with autoinflammatory diseases. Pediatr Nephrol 31:633-640

\section{Submit your manuscript to a SpringerOpen ${ }^{\circ}$ journal and benefit from:}

- Convenient online submission

- Rigorous peer review

- Immediate publication on acceptance

- Open access: articles freely available online

- High visibility within the field

- Retaining the copyright to your article 